simple explanation. However, a larger study is required to establish new references. The latest British growth standards were developed in 1990, but less than a decade later it has become evident that these standards no longer reflect the distribution of weight in British schoolchildren.

The cause for concern is twofold. Firstly, cohort studies show that obesity may track from childhood to adulthood, where morbidity is very evident. Secondly, obesity in adolescence is directly associated with increased morbidity and mortality in adult life independent of adult body weight. This study lends further support to reports that levels of obesity in Britain are increasing at an appreciable rate in primary school children, that the measures of skinfold at the triceps need to be revalidated, and that this major public health issue needs urgently addressing in young children.

Contributors: MCJR was the principle investigator of the active programme promoting lifestyle education in school project. She conceived and designed the article, analysed and interpreted the data, and drafted the manuscript. She will act as guarantor for the paper. PS was the project manager of the active programme promoting lifestyle education in school project, analysed the raw data, discussed core ideas, and revised the article for intellectual content. JHB discussed the core ideas and edited the article. JW collected the anthropometric data and also discussed core ideas.

Funding: This research was supported by a grant from NHS Northern and Yorkshire Region Research and Developmen Unit. The Castlemead Growth Programme 1993, a software package produced by Castlemead, was used to analyse the body mass index and triceps data.

Competing interests: JHB has received consultancy fees from Roche Pharmaceuticals.

1 Reilly JJ, Dorosty AR, Emmett PM. Prevalence of overweight and obesity in British children: cohort study. BMJ 1999;319:1039.

2 Reilly JJ, Dorosty AR. Epidemic of obesity in UK children. Lance 1999;354:1874-5

3 Sahota P, Rudolf MCJ, Dixey R, Hill AJ, Barth JH, Cade J. APPLES: a primary school based randomised controlled trial to reduce obesity risk factors. $B M J$ (in press)

4 Tanner JM, Whitehouse RH. Revised standards for triceps and subscapular skinfolds in British children. Arch Dis Child 1975;50:142-5.

5 Cole TJ, Freeman JV, Preece MA. Body mass index reference curves for the UK, 1990. Arch Dis Child 1995;73:25-9.

(Accepted 21 December 2000)

\title{
Age of menarche in contemporary British teenagers: survey of girls born between 1982 and 1986
}

\author{
P H Whincup, J A Gilg, K Odoki, S J C Taylor, D G Cook
}

The possibility that puberty is occurring earlier in Britain than previously has caused great interest. ${ }^{1}$ Despite the importance of menarcheal age as an indicator of puberty, ${ }^{2}$ there is little information on menarcheal age in contemporary teenagers to compare with data on girls born in the 1950s and $1960 \mathrm{~s}$. We report on the distribution of menarcheal age in a survey of British girls born between 1982 and 1986.

\section{Participants, methods, and results}

In 1998-9 we studied the cardiovascular health of secondary school children aged 12-16 in schools in 10 British towns: five in southern England (Esher, Leatherhead, Chelmsford, Bath, Tunbridge Wells), three in north west England (Wigan, Burnley, Rochdale), and two in south Wales (Port Talbot, Rhondda). We approached those secondary schools corresponding to a stratified random sample of primary schools in our earlier study ${ }^{3} ; 62$ of $65(95 \%)$ with female pupils participated. In each school we invited girls from the earlier study to participate, with a supplementary random sample of pupils from the same classes. ${ }^{3}$ During screening the girls completed a confidential self administered questionnaire on date of birth, whether they had started their periods and, if so, their age (years and months) at the first period. Social class was based on parental occupation (using the Registrar General's 1990 classification). Ethnicity was based on appearance and cross checked with surname and parental self assessment. We used SAS (version 6.12) for the statistical analysis. We determined the median age of menarche and confidence intervals using survival analysis with PROC LIFETEST. We included girls who had not yet had their first period (88 participants); for girls providing only year of menarche (231), the month was imputed using the mean value for other girls of the same age in years. Probit transformation ${ }^{2}$ of the percentage of affirmative responses at each age gave almost identical results. In all, 1166 girls aged 12-16 years (1068 European, 79 South Asian, 19 other) reported their menarcheal age (response 66\%). The median menarcheal age was 12 years 11 months (95\% confidence interval 12 years 10 months to 13 years 1 month). The percentages of girls who reported having had their first period by their 10th, 11th, or 12th birthdays were $0.8,3.6$ and 21.7, respectively; $11.8 \%$ had their first period before leaving primary school. Median ages of menarche were similar in different regions (table) and did not differ by social class or ethnic group (see table on website). Non-responders closely resembled responders in age and geographical location.

\section{Comment}

The median age of menarche in contemporary British teenagers is around 13 years. In our study geographical, social, and ethnic variations were small, suggesting that non-response bias in menarcheal age was likely to be limited. Comparison with British girls born between 1950 and 1965 (table) suggests that the median menarcheal age reported here is close to or slightly below the earlier findings. Two points emerge clearly from the results. Firstly, any decrease in average menarcheal age during the past 20-30 years has been small (almost certainly less than six months), particularly when compared with the reduction of a year or more that occurred in many European countries (including Britain) between the late 19th
Regional Paediatric Endocrinology Clinic, Leeds General Infirmary, Leeds LS1 3EX

Julian H Barth consultant in chemical pathology and metabolic medicine Jenny Walker auxologist

Correspondence to: M C J Rudolf Mrudolf@ulth. northy.nhs.uk

Department of Public Health Sciences, St George's Hospital Medical School, London SW17 0RE P H Whincup professor of cardiovascular epidemiology J A Gilg research statistician K Odoki clinical research fellow D G Cook professor of epidemiology

Department of General Practice and Primary Care, Medical Sciences, Queen Mary and Westfield College, London E1 4NS S J C Taylor senior clinical lecturer Correspondence to: P H Whincup p.whincup@ sghms.ac.uk

BMJ 2001;322:1095-6 bmi.com

A figure showing age at menarche, a longer version of the table, and details of the previous studies appear on the $B M J$ 's website 
Age of menarche in contemporary British teenagers and those born between 1950 and 1965

\begin{tabular}{|c|c|c|c|c|}
\hline Reference & Region & $\begin{array}{c}\text { No of } \\
\text { participants }\end{array}$ & Date of birth & $\begin{array}{l}\text { Median age of menarche } \\
(95 \% \mathrm{CI})\end{array}$ \\
\hline Tanner $^{4}$ & London & 7000 & $1950-7$ & 13.0 (12.9 to 13.1$)$ \\
\hline Roberts et al ${ }^{\mathrm{w} 1}$ & $\begin{array}{l}\text { North east } \\
\text { England }\end{array}$ & 1307 & $1954-9$ & 13.3 (13.2 to 13.4$)$ \\
\hline Billewicz et al'w2 & $\begin{array}{l}\text { North east } \\
\text { England }\end{array}$ & 699 & 1962 & 13.4 (13.3 to 13.5$)$ \\
\hline Roberts et al ${ }^{\mathrm{v} 3}$ & $\begin{array}{l}\text { North west } \\
\text { England }\end{array}$ & 1274 & $1960-5$ & $13.3(13.2$ to 13.4$)$ \\
\hline \multicolumn{5}{|l|}{ Current study } \\
\hline & $\begin{array}{l}\text { Southern } \\
\text { England }\end{array}$ & 575 & $1982-6$ & 13.1 (12.8 to 13.2 ) \\
\hline & $\begin{array}{l}\text { North west } \\
\text { England }\end{array}$ & 358 & & $12.9(12.7$ to 13.2$)$ \\
\hline & South Wales & 233 & & 12.9 (12.6 to 13.2$)$ \\
\hline Overall & & 1166 & & $12.9(12.8$ to 13.1$)$ \\
\hline
\end{tabular}

Medians determined using probit method in earlier studies and survival analysis in current study.

and mid 20th centuries. ${ }^{2}$ Secondly, even though no appreciable recent decrease in menarcheal age has occurred, almost one girl in eight reaches menarche while still at primary school. This needs to be taken into account when providing sanitary facilities and health information for female pupils in primary school.

We thank all the participants for their help.

Contributors: PHW and DGC had the idea for the paper and designed the study with support from KO and SJCT. JAG carried out the analyses. PHW drafted the paper, with contributions from all authors. PHW and DGC will act as guarantors for the paper.

Funding: This study was funded by the Wellcome Trust (grant 051187/Z/97/A)

Competing interests: None declared.

1 Ellen B. Too much, too young... Observer, 18 Jun 2000;1:4.

2 Eveleth PB, Tanner JM. Worldwide variation in human growth, 2nd ed. Cambridge: Cambridge University Press, 1990.

3 Whincup PH, Cook DG, Adshead F, Taylor S, Papacosta O, Walker M, et al. Cardiovascular risk factors in British children from towns with widely differing adult cardiovascular mortality. BMJ 1996;313:79-84.

4 Tanner JM. Trend towards earlier menarche in London, Oslo, Copenhagen, the Netherlands and Hungary. Nature 1973;243:95-6.

(Accepted 15 December 2000)
Lothian Primary Care NHS Trust, Edenhall Hospital, Musselburgh EH21 7TZ

Janet Hanley research manager

Royal Victoria Hospital, Edinburgh EH4 2DN

Ann Capewell consultant physician in medicine of the elderl

Nursing Research Initiative for Scotland, Faculty of Health, Glasgow

Caledonian

University, Glasgow G4 0BA

Suzanne Hagen research adviser/ statistician

Correspondence to: J Hanley Janet.Hanley@lpct. scot.nhs.uk

BMJ 2001;322:1096-7
Lack of a universally accepted, easily applied, outcome measure is one reason why urinary incontinence in women is poorly evaluated and treated. ${ }^{1}$ The severity index, developed by Sandvik et al, is short and simple enough for use in almost any context. ${ }^{2}$ We evaluated the reliability, validity, and sensitivity to change of the severity index in a wide range of women in Scotland.

\section{Methods and results}

The severity index comprises the following two questions. How often do you experience urine leakage $(0=$ never, $1=$ less than once a month, $2=$ one or several times a month, $3=$ one or several times a week, $4=$ every day and/or night)? How much urine do you lose each time $(1=$ drops or little, $2=$ more $)$ ? The total score is the score for the first question multiplied by the score for the second question $(0=$ dry, $1-2=$ slight, $3-4=$ moderate, $6-8=$ severe). We added the category "dry" for women whose urinary incontinence was cured. A version of the index splitting the "severe" category into severe and very severe has recently been

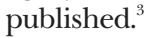

To investigate test-retest reliability, the revised index was administered to study participants twice, three days apart. To assess validity, 48 hour urinary diaries and measures of urine leakage over 48 hours (calculated by weighing of pads) were collected. To test sensitivity to change, participants being treated for their urinary incontinence completed the measures again 12 weeks after either surgery or first attendance at a non-surgical continence clinic. Age, physical disability (Barthel index), ${ }^{4}$ and cognitive disability (abbreviated mental test) were also recorded. ${ }^{5}$

Data were collected from women with stable incontinence not undergoing treatment, identified via community nurses; women undergoing initial assessment and non-surgical treatment at a continence clinic; and women awaiting surgical treatment (colposuspension) for stress incontinence. Those included were medically stable and either were cognitively intact (abbreviated mental test $\geqslant 8$ ) or had a carer to help them.

Overall, 237 women were recruited (table). Community patients were significantly older $\left(\mathrm{F}_{2234}=113.6, \mathrm{P}<0.001\right)$, more cognitively impaired (Kruskal-Wallis $\chi^{2}=34.1, \mathrm{P}<0.001$ ), and more physically disabled $\left(\chi^{2}=88.8, \mathrm{P}<0.001\right)$ than women in the two treatment groups. They also experienced greater urine leakage $\left(\chi^{2}=31.6, \mathrm{P}<0.001\right)$ and more episodes of incontinence $\left(\chi^{2}=26.8, \mathrm{P}<0.001\right)$.

Most women $(202 ; 88 \%)$ recorded the same severity index response category on days 1 and $4(\kappa=0.78$, $\mathrm{P}<0.001)$. Test-retest reliability for each question was also $\operatorname{good}(\kappa=0.69$ for question 1 and 0.83 for question $2, \mathrm{P}<0.001$ for both).

Higher severity index categories were associated with increasing urine leakage $(r=0.36, \mathrm{P}<0.001)$. Median urine leakage over 48 hours was $32 \mathrm{~g}$ for those in the "slight" category, $29 \mathrm{~g}$ for "moderate," and $143 \mathrm{~g}$ for "severe" $\left(\chi^{2}=14.9, \mathrm{P}<0.001\right.$; mean ranks 41.8, 50.2, and 80.7 respectively). There was a similar association between severity index category and number of episodes of incontinence $(r=0.55, \mathrm{P}<0.001)$. The 